\title{
Influence of Emotional Labour on Burnout among Nurses:
}

\section{A Sem Approach}

\section{Kaur S*}

Assistant Professor, Guru Nanak Institute of Management and Technology, India

*Corresponding author: Sandeep Kaur, Assistant Professor, Guru Nanak Institute of Management and Technology, Ludhiana, India, Tel: 9888995523; Email: sandeepsaimbhi@gmail.com

\section{Research Article}

Volume 2 Issue 1

Received Date: February 12, 2019

Published Date: February 25, 2019

DOI: $10.23880 /$ jqhe- 16000111

\section{Abstract}

Background: Over the last few years, India is experiencing a revolution in health care sector. Due to increase in diseases, it has become the responsibility of hospitals and medical staff to provide the best facilities and the personal touch to the services rendered to the patients. While doing this job, the employees have to undergo through emotional labour and burnout.

Objectives: The objective of this study is to find out the influence of emotional labour on burnout among nurses of selected public and private hospitals of Punjab. The total number of nurses under study was 592.

Method: The Dutch Questionnaire on Emotional Labor (D-QEL) developed and validated by Nearing, et al. (2005) and burnout tool by Pines, et al. (1988) was used to assess physical, mental and emotional exhaustion.

Results: Descriptive statistics was applied to check the level of emotional labour and burnout, while structural equation modeling technique was applied to find out the influence of emotional labour on burnout. Results showed that employees in selected hospitals of Punjab had moderate level of emotional labour and burnout. There was a positive significant correlation between emotional labour and burnout. Emotional labour emerged as the significant predictor of burnout as standardized regression coefficient of emotional labour and burnout was 0.74 .

Recommendations: Hospital authorities should provide emotional assistance to their employees by providing their employees with recreational clubs, yoga training, seminars, etc.

Keywords: Emotional labour; Burnout; Employees and Hospitals

\section{Introduction}

Human Resource Department is facilitating the organizations for the better utilization of human potential as they are the most precious asset of all the organizations. Human being has the capacity to direct the world. They have the power of logic, reasoning, will and most importantly the emotions which separate them from the other living beings. Development of the service sector and an increase in the level of interaction between the employees and the customers has made emotions of employees an important and integral part of labour which 


\section{Journal of Quality in Health Care \& Economics}

they have to do for their job. Over the last few years, India is experiencing a revolution in the health care sector. Indian healthcare sector, especially the hospitals are at par with western countries. The people living in other countries are coming to India for the best health care facilities at the cheapest rates as medical tourism. For providing best services to the patients, employees of these hospitals have to undergo through emotional labour process which results in negative outcomes like burnout. The present empirical study is conducted to find the influence of emotional labour on burnout.

Emotional labour had been used in describing emotion as part of work. Emotional labour was the control of the behavior to display the appropriate emotions. Hochschild [1] found that emotional labour was required in jobs that involved face-to-face or voice-to-voice contact with the public; required a worker to produce an emotional state in another person; allowed the employer, through training and supervision, to exercise a degree of control over the emotional activities of employees. Ashforth and Humphrey [2] defined that "emotional labor occurred when labourer deliberately attempted to direct his or her behavior towards others in order to foster both a certain social perception and a certain interpersonal climate. Morris and Feldman [3] described that during interpersonal transactions emotional labor could be defined as an effort, planning and control needed to express organizationally desired emotion. Frequency of interactions, attentiveness like intensity of emotions, duration of interaction, variety of emotions required and emotional dissonance were the four proposed dimensions of emotional labour. According to this perspective, emotional labor was a characteristic of the job. Grandey [4] defined emotional labour as the process of regulating both feelings and expression for the organizational goals. Bernard [5] admitted that these days the expression mainly used in service sector are "labour of love", and "labour with a smile", "comforting labour". Emotional labour could be considered as a subjective effort as there is capacity for self-development.

There are two types of emotional labour namely: surface acting and deep acting.

- Surface Acting: Surface acting involved "painting on" an affective displays or faking of emotions. In surface acting an employee would be presenting his or her emotions without actually feeling them. He put on a "persona (a mask)" and pretend as if the emotions were felt within.

- Deep Acting: Mainly, there are two different emotional actions in deep acting. First is to exhibit the actual emotions that one could feel. The second emotional action means ability to allow past emotional experiences to encourage real emotion that one might not have felt otherwise. Hsieh and Yang [6] confirmed that emotional labour was important for public service work and recently had gained significant attention from public administration scholars. Hennig, et al. [7] examined the effects of two impacts of employee emotions on customers. They investigated the influence of these display of positive emotions on service employees and found that authenticity of employee's emotional labor of employees which directly affected consumer's, emotional state. The smiles of employees did not influence customer emotions.

Many professions like hospitality sector, hospitality professionals, counselors and therapists, psychologists, actors, receptionists, air-hostesses had emotional labour as integral part of their profession.

These days, due to heavy workload, high competition and organizational role stress, a large number of qualified, energetic and productive employees are in the flames of burnout. Burnout was first coined by American psychiatrist Freudenberger in 1970s. Burnout could be considered as a feeling of emotional and physical exhaustion attached with a deep sense of frustration and failure. A social psychologist Christina Maslach [8] with her colleagues began to explore the loss of emotional feeling and concern for clients among human services professionals. Burnout was primarily a work-related illness caused by an imbalance in an individual's personal goals, ideals, and needs as related to their job, but sometimes stresses and factors outside the workplace could also contribute to the problem. Wolfe [9] found burnout to be a pervasive and unbearable syndrome within the services professions. The causes of burnout were namely: failure to meet the goal; work overload, role conflict and strategies for coping were suggested. In Mosby's Dictionary of Complementary and Alternative Medicine, Jonas [10] defined burnout as a state that occurs when energy is used up faster than it is restored. The main dimensions of burnout were emotional exhaustion, depersonalization and personal accomplishment. Emotional exhaustion could be referred as a depletion of emotional resources. Emotionally exhausted employees typically felt as though they lack adaptive resources and could not give any more to their job. Depersonalization was also known as cynicism and disengagement in the academic literature. Depersonalization was an attempt to get distance between oneself and service recipients by actively ignoring the qualities that made them unique. The third 


\section{Journal of Quality in Health Care \& Economics}

component of burnout was characterized by a tendency to evaluate one's behavior and performance negatively.

\section{Review of Literature}

Researchers have confirmed that job demand, job control and job burnout were very much high in employees who were performing emotional labour in comparison to those who were not performing it. Following are the few studies advocating the above said: Grandey, et al. [11] found that there was a positive relationship between stress, appraisal of customer aggression with emotional exhaustion and this mediated the relationship of stress appraisal with absences. The employees who felt threatened by customer aggression used surface acting while deep acting was used by those who were less threatened by their customers. Warhurst, et al. [12] claimed that workers who perform emotional labour under conditions of low job autonomy or high job involvement were more at risk of emotional exhaustion than others who did not perform this. Mohammedyfar, et al. [13] expressed that emotional intelligence and occupational stress were explained $43.9 \%$ of variance of mental health in Indian teachers sample. The teachers who had reported higher emotional intelligence had better mental health. Emotional intelligence and burnout explained $13.5 \%$ of variance of physical health. Noor, et al. [14] showed that there was a positive association of surface acting with emotional exhaustion and depersonalization. Work-family conflict mediated the relationship between emotional labor and burnout. Kim, et al. [15] showed that the mean values of job satisfaction, job insecurity, and the level of depressive symptoms of the employees who were working in the area of emotional labor were higher than the others. Brotheridge, et al. [16] compared two perspectives of emotional labor as predictors of burnout beyond the effects of negative affectivity i.e. job-focused emotional labor and employee focused emotional labor. It was reported by five occupational groups that there existed significant differences in emotional demands. Surface level emotional labor (faking) predicted depersonalization beyond the work demands. Celik, et al. [17] found relationship between the emotional labour and burnout displayed by the nurses, the employees of one of the career groups in which high level of interaction with the human beings occur, it had been determined that there was a correlation between emotional labour with its subdimensions, and burnout with its sub-dimensions.

\section{Need of the Study}

Due to the technological advancement and global competition the electronic gadgets, mobiles, air and water pollutions have increased the diseases like cancer, Hepatitis A, B, C, AIDS, brain hem rage, strokes etc. To meet the requirements of the patients, nurses have to do tough jobs in hospitals. Hospital sector has been chosen for the study as nurses give the new life to the patients. To meet all these requirements of the society, nurses go through the process of emotional labour to conceal their real feelings to deliver the best possible services in hospital sector. Doing this emotional labour at the work, nurses have to undergo emotional exhaustion which leads to conflicts at home and this vicious circle starts developing the syndrome of burnout. In the present study, the researcher finds whether there is any influence of emotional labour on burnout among nurses. This study is an attempt to provide insights to manage emotions and burnout.

\section{Objectives of the Study}

The main objectives of the present study are as follows:

1. To study the relationship between emotional labour and burnout among nurses in selected hospitals.

2. To find out the influence of emotional labour on burnout among nurses in selected hospitals of Punjab.

\section{Hypotheses of the Study}

- H1: There is a significant relation between dimensions of emotional labour and burnout among nurses in selected hospitals.

- H3: There is a significant influence of emotional labour on burnout among nurses in selected hospitals.

\section{Research Methodology}

\section{Research Design}

The present study is descriptive cum empirical in nature. Independent Variable: The present study has one independent variable emotional labour. Emotional labour comprises of four dimensions; surface acting, deep acting, emotional consonance and suppression

Dependent Variable: Burnout is the dependent variable in the present study. It comprises of three dimensions physical exhaustion, mental exhaustion and emotional exhaustion.

Scope of the Study and Sample Size: Scope of the study is confined to cover emotional labour, and burnout among nurses in selected hospitals of Punjab. The total population is 592 which comprises of nurses of six public and private selected hospitals of Punjab. The respondents 


\section{Journal of Quality in Health Care \& Economics}

were taken from those hospitals which have bed capacity of 100 or more. A sample of nurses has been chosen using stratified random sampling.

Sampling Technique and Sample Design: Primary data was collected through Stratified random sampling technique. Data was collected from strata of nurses on random basis. Secondary data was collected from books, magazines, journals, periodicals and libraries.

Description of Tools: The questionnaire was divided into two sections; Section-A: constituted demographic details as: name of the hospital, age, gender, marital status, designation, years of experience, type of the hospital. Section-B: emotional labour questionnaire and burnout questionnaire. The Dutch Questionnaire on emotional labor (D-QEL) was used which was developed and validated by Nearing, et al. [18]. The scale was a multidimensional scale consisting subscales surface acting, deep acing, emotional consonance and suppression. Responses were obtained on five point Likert scale. The reliability of the scale was 0.663 . Burnout developed by Pines and Aronson [19] was used to assess physical, mental and emotional exhaustion. The 21 stress related items were asked on Likert scale. The reliability of burnout scale was found to be 0.732

\section{Results}

Descriptive statistics, correlation and regression analysis was done on SPSS 17.0 version. The following table 1 presents the frequency distributions of demographic variables of nurses in selected hospitals.

\begin{tabular}{|c|c|c|c|c|}
\hline \multirow{4}{*}{ Age } & Groups & Public & Private & Total \\
\cline { 2 - 5 } & $25-30$ & 152 & 170 & 322 \\
\cline { 2 - 5 } & $31-35$ & 70 & 52 & 122 \\
\cline { 2 - 5 } & $36-40$ & 38 & 37 & 75 \\
\cline { 2 - 5 } & $41-45$ & 16 & 14 & 43 \\
\cline { 2 - 5 } & 45 and above & 23 & 20 & $\mathbf{5 9 2}$ \\
\cline { 2 - 5 } & Total & $\mathbf{2 9 9}$ & 34 & 520 \\
\cline { 2 - 5 } & Male & 38 & 259 & $\mathbf{5 9 2}$ \\
\cline { 2 - 5 } & Female & 261 & $\mathbf{2 9 3}$ & 285 \\
\hline \multirow{4}{*}{ Marital Status } & Total & $\mathbf{2 9 9}$ & $\mathbf{2 9}$ & $\mathbf{5 9 2}$ \\
\cline { 2 - 5 } & Unmarried & 108 & $\mathbf{2 9 3}$ & 329 \\
\cline { 2 - 5 } & Married & 191 & 180 & 127 \\
\cline { 2 - 5 } & Total & $\mathbf{2 9 9}$ & 58 & 57 \\
\cline { 2 - 5 } & $0-5$ & 149 & 22 & 32 \\
\cline { 2 - 5 } & $5.1-10$ & 69 & 17 & 43 \\
\cline { 2 - 5 } & $10.1-15$ & 35 & 16 & \\
\cline { 2 - 5 }
\end{tabular}

Table 1: Demographic Variables of respondents (Hospital-wise).

Table 1 describes the complete description of the respondents on demographic variables namely: age, gender, marital status and years of experience.

Descriptive statistics for emotional labour and burnout is given in table 2 . The mean score of emotional labour is 3.03 and for burnout is 2.86 which means that comparatively emotional labour is on higher level and burnout is on the moderate level among nurses of selected hospitals of Punjab. The results were in line with Patrick and Lavery. They found Victorian nurses were not experiencing high levels of burnout and the vast majority was satisfied with their career choice.

\begin{tabular}{|c|c|c|c|c|c|c|c|c|c|c|c|}
\hline & Mean & S.D & SAEL & DAEL & ECEL & SUEL & PEB & MEB & EEB & EL & B \\
\hline SAEL & 2.7645 & 0.7554 & 1 & & & & & & & & \\
\hline DAEL & 3.0372 & 0.7866 & 0.405 & 1 & & & & & & & \\
\hline ECEL & 3.3387 & 0.8811 & 0.395 & 0.408 & 1 & & & & & & \\
\hline SUEL & 3.0563 & 0.8115 & 0.364 & 0.492 & 0.408 & 1 & & & & & \\
\hline
\end{tabular}




\section{Journal of Quality in Health Care \& Economics}

\begin{tabular}{|c|c|c|c|c|c|c|c|c|c|c|c|}
\hline PEB & 2.9689 & 0.6339 & 0.512 & 0.364 & 0.357 & 0.272 & 1 & & & & \\
\hline MEB & 2.7838 & 0.6454 & 0.458 & 0.364 & 0.186 & 0.269 & 0.477 & 1 & & & \\
\hline EEB & 2.861 & 0.5733 & 0.487 & 0.391 & 0.35 & 0.304 & 0.49 & 0.56 & 1 & & \\
\hline EL & 3.0492 & 0.6049 & 0.71 & 0.765 & 0.757 & 0.758 & 0.5 & 0.419 & 0.509 & 1 & \\
\hline B & 2.8712 & 0.5064 & 0.592 & 0.454 & 0.36 & 0.342 & 0.805 & 0.835 & 0.82 & 0.578 & 1 \\
\hline
\end{tabular}

* Correlation is significant at the 0.05 level and ${ }^{* *}$ at 0.01 level of significance.

Table 2: Means, standard deviations and inter-correlations of dimensions of Emotional labour and Burnout.

Table 2 also represents inter-correlations between emotional labour, four strain outcomes (surface acting, deep acting, emotional consonance and suppression) and burnout (physical exhaustion, mental exhaustion and emotional exhaustion). Among all the dimensions of emotional labour, emotional consonance was on higher side. Surface acting was the least adopted strategy among nurses which means that, nurses were not faking emotions rather they can easily express their feelings to their patients. Burnout level was on moderate level. Significant positive correlation $\mathrm{r}=.578$ was observed between the dimensions of emotional labour and burnout. The results of the present study are in line with Ndetei, et al. [20]. They found that out of a sample of 530 nurses working in psychiatric hospitals, $95 \%$ of the respondents reported low to high emotional exhaustion while $87.8 \%$ reported depersonalization. Low accomplishment was reported by only $38.6 \%$ while $61.4 \%$ reported average to high personal accomplishment. Several work- and nonwork-related factors including young age, number of own children, number of years worked, heavy workload and low morale were positively associated with various syndromes of burnout. Relationships at work, with family and society were generally rated as average.

\section{Association between Emotional Labour and Burnout with Demographic Variables}

To find out whether there is a significant association between demographic variables and variables under study, t-test and ANOVA were applied. The results are depicted below.

\begin{tabular}{|c|c|c|c|c|}
\hline \multirow{2}{*}{ Source of Variation } & \multicolumn{2}{|c|}{ Emotional Labour } & \multicolumn{2}{|c|}{ Burnout } \\
\cline { 2 - 5 } & $\mathbf{t} \backslash$ F-value & $\mathbf{p}$ - value & $\mathbf{t} \backslash$ F-value & p- value \\
\hline Age & 2.247 & 0.063 & 2.966 & $.019^{*}$ \\
\hline Gender & -0.164 & 0.87 & -1.495 & 0.136 \\
\hline Marital Status & 0.668 & 0.505 & 2.858 & $.004^{*}$ \\
\hline Type of Hospital & -2.969 & $.003^{*}$ & -2.487 & $.013^{*}$ \\
\hline Years of Experience & 0.944 & 0.438 & 1.601 & 0.173 \\
\hline
\end{tabular}

Table 3: T-test and one way ANOVA of demographic variables on outcome of Emotional labour and Burnout.

From the above table 3, it had been observed that for demographic variable i.e. age, there was no significant difference in the level of emotional labour (F-value $=2.247$, $\mathrm{p}=.063>0.05)$ but there was significant difference in the level of burnout (F-value $=2.966, \mathrm{p}=.019<0.05)$. Further, Boneferri was used to find the difference in the age categories and it was found that age group 25-30 years and 31-36 years and above had more burnout than the other age groups.

For gender, there was no significant difference in the level of burnout and emotional labour. For marital status, there was no significant difference in the level of emotional labour but there was significant difference in the level of burnout ( $\mathrm{t}$ value $=-3.213, \mathrm{p}=.001<0.05$ ) among nurses. Unmarried nurses had more burnout with their job than married nurses.
For different type of hospitals, there was significant in the level of emotional labour. Private hospital nurses had more emotional labour than public hospital nurses. Also, private hospital nurses had more burnout than nurses in private hospitals.

For demographic variable i.e. years of experience, there was no significant difference in the level of burnout and emotional labour for different experience categories.

To examine the influence of emotional labour on job satisfaction, structural equation modeling technique was applied. For this, measurement model for emotional labour and job satisfaction was evaluated separately. In the measurement model, critical ratio of standardised regression weight of each variable had been checked to establish whether it was significant or not at the 


\section{Journal of Quality in Health Care \& Economics}

established confidence level. Afterwards model fits was determined. Goodness of fit statistics produced by AMOS (Analysis of Moment Structure) software was used to evaluate whether or not the measurement model fit the data. The final stage of statistical analysis was Structural Equation Modeling (SEM), a statistical process that assesses how well the collected sample data fits to the theoretically driven developed model as shown in table 3.

To examine the influence of emotional labour on burnout, structural equation modeling technique was applied. For this, measurement model for emotional labour and burnout was evaluated separately. In the measurement model, critical ratio of standardised regression weight of each variable has been checked to establish whether it was significant or not at the established confidence level. Afterwards model fit was determined. Goodness of fit statistics produced by AMOS software was used to evaluate whether or not the measurement model fit the data. The final stage of statistical analysis is Structural Equation Modeling (SEM), a statistical process that assesses how well the collected sample data fit to the theoretically driven developed model as shown in table 4 .

\section{Assessing Structural Model Validity for Emotional Labour}

SEM was applied to explore the relationship between the unobserved variables within the structural model. The structural model showed the influence of emotional labour i.e. surface acting, deep acting, emotional consonance and suppression on burnout.

\section{Goodness of Fit Statistics for the Model}

The main values for measurement models were: CMIN, CFI, RAMESA, and HOLETAR. The values of CMIN should be near to value 3 approximately and value of CFI should be greater than .90 and RAMESA and HOLETAR should be approximately equal to .05 .

\begin{tabular}{|c|c|}
\hline Index & Criteria Values \\
\hline GFI & \multirow{2}{*}{$0.80 \leq$ value $<0.90$; acceptable $\geq 0.90$; good } \\
\cline { 1 - 1 } AGFI & $0.90 \leq$ value $<0.95$; acceptable $\geq 0.95$; good \\
\hline NFI & $0.05<$ value $\leq 0.08$; acceptable $\leq 0.05$; good \\
\hline CFI & Smaller the better \\
\hline RAMESA & P>=0.05 \\
\hline LO90 & $\leq 2 ; \leq 3 ; \leq 4$ \\
\hline Chi square & \\
\hline Chi square associated p value &
\end{tabular}

Table 4: Index Criteria for fitting of Model.

In the proposed measurement model, CMIN value is 2.097, CFI is .981, RAMESA was .043 and HOLETAR was .05 which satisfied the required criteria for measurement model. This model was best fit. Standardized factor loadings of all the indicator variables were within the range of 0.80 to $0.9(>0.50)$. All factor loadings and correlations between measurement error terms were statistically significant at $\mathrm{p} \leq 0.05$ as they should be (Table 5).

\begin{tabular}{|c|c|c|c|c|c|c|}
\hline GFI & AGFI & CMIN/DF & CFI & NFI & RMSEA & L090 \\
\hline 0.968 & 0.953 & 2.097 & 0.98 & 0.965 & 0.043 & 0.033 \\
\hline
\end{tabular}

Table 5: Model fit Summary for Emotional labour.
The measurement model of emotional labour had shown excellent fit to the obtained data in terms of all the selected goodness-of-fit statistics. All factor loadings and correlations between measurement error terms were statistically significant at $\mathrm{p} \leq 0.05$.

Checking the critical ratio of standardized regression weight of each indicator and structural path between variables demonstrates that all factor loadings of latent constructs and structural paths from both emotional labour to overall burnout are significant at $\mathrm{p}<0.05$. The sign of the standardized path coefficients are all positive which means that they are in the right direction (Figures 1-3). 


\section{Journal of Quality in Health Care \& Economics}

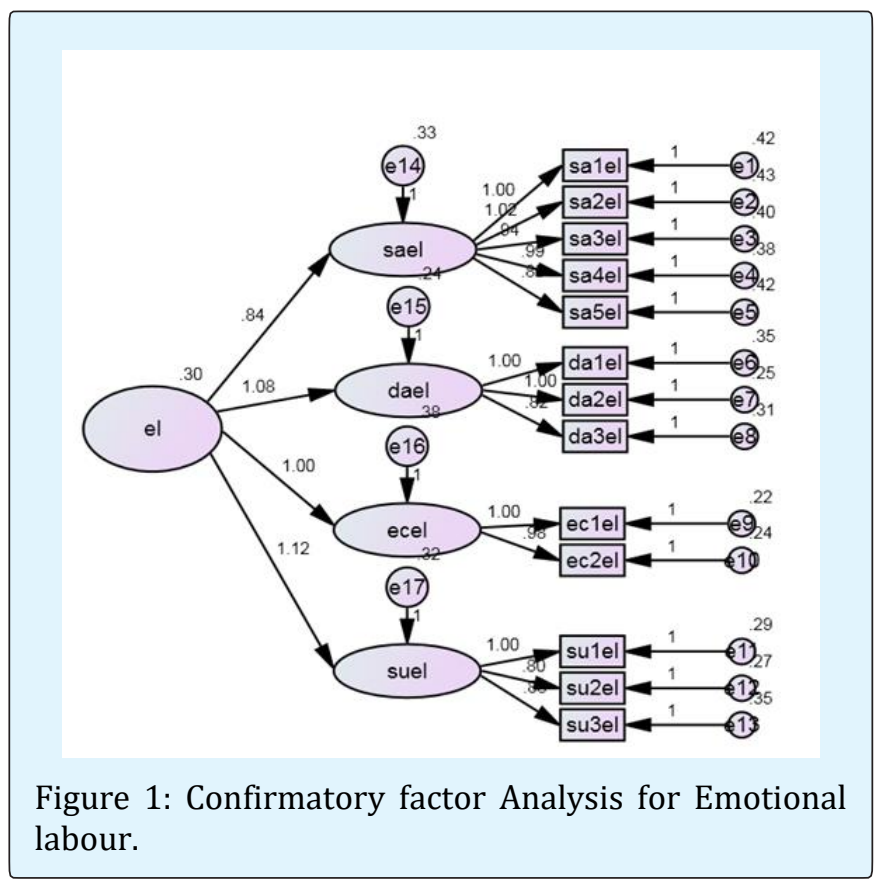

\section{Assessing Structural Model Validity for Burnout}

For assessing the model fit for burnout GFI, AGFI, CMIN, CFI, NFI and RAMESA were calculated. The proposed model fit had CFI value .899, GFI was .866, AGFI was .859 and RAMESA was .068. All the values were within the range as shown in the table 6 .

\begin{tabular}{|c|c|c|c|c|c|c|}
\hline GFI & AGFI & CMIN/DF & CFI & NFI & RMSEA & L090 \\
\hline 0.886 & 0.86 & 3.739 & 0.899 & 0.867 & 0.068 & 0.063 \\
\hline
\end{tabular}

Table 6: Model fit summary for Burnout.

The measurement model of burnout showed moderate fit to the obtained data. In terms of all the selected goodness-of-fit statistics. The main values for measurement models were CMIN, CFI, RAMESA, and HOLETAR. The values of CMIN should be near to value 3 approximately and value of CFI should be greater than .90 while RAMESA and HOLETAR should be approximately equal to .05. In the above measurement model, CMIN value was 3.739 , CFI is .899, RAMESA is .068 and HOLETAR was .05 which satisfied the required criteria for measurement model. This model was moderate fit.

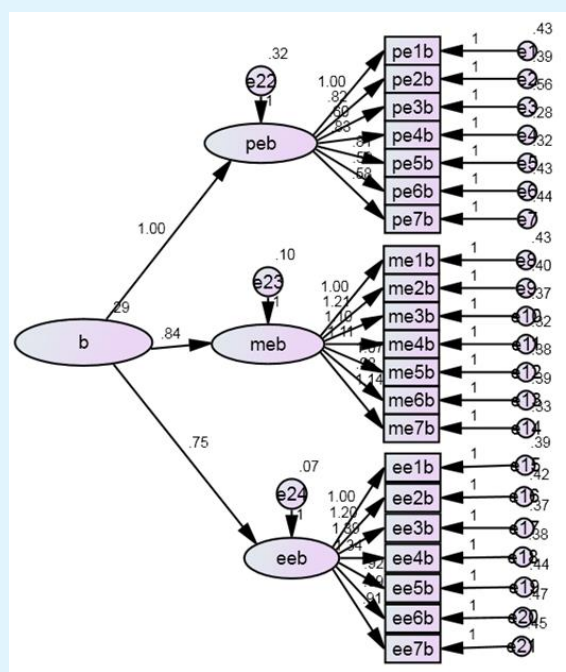

Figure 2: Confirmatory factor Analysis for Burnout.

\section{Structural Equation Modeling}

Structural equation modeling was applied to develop a relationship among independent variable i.e. emotional labour and dependent variable i.e. burnout. The results of AMOS output proved that there was a positive correlation between emotional labour and burnout. The regression coefficient of emotional labour in burnout was 0.74. From the analysis, it was found that all the dimensions of burnout had a positive regression coefficient i.e. which indicated that if the emotional labour increased then burnout also increased. For $1 \%$ change in emotional labour there would be $.74 \%$ change in burnout.

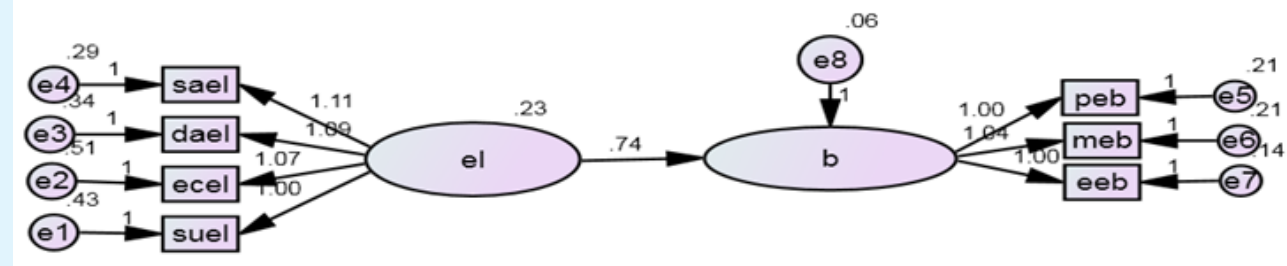

Figure 3: Relationship between Emotional labour and Burnout. 


\section{Journal of Quality in Health Care \& Economics}

For the relationship between burnout and its dimensions, it was found that emotional consonance and suppression have less influence on burnout.

\section{Testing Hypotheses}

H1: There is significant influence of emotional labour on burnout According to the model, emotional labour had been a significant predictor of burnout. For the endogenous variable of overall burnout, results from the SEM showed that emotional labour was positively and significantly related to burnout, as anticipated by the study theory, with standardized regression weights of 0.74 . It means that emotional labour has positive effect on burnout.

\section{Major Findings and Discussions}

- The findings of the present study supported the hypothesis that there is a significant influence of emotional labour on burnout of the employees in selected hospitals of Punjab.

- Emotional labour was positively related with burnout.

- Out of various dimensions of emotional labour: surface acting and deep acting had emerged as major cause of burnout

The results of present study were in line with Kinman, et al. [21]. They reported that the teachers who reported more emotional labour were not only more emotionally exhausted and less satisfied with their work but they were also more likely to depersonalize their pupils. It was possible that teachers developed less sympathetic and more cynical attitudes towards their pupils. In current study, employees of selected hospitals had moderate level of emotional labour and burnout. This was also supported by Sutton [22]. He found that teachers who performed more emotional labour, tended to report higher rather than lower levels of personal accomplishment.

Surface acting strategy influenced burnout positively but emotional consonance did not positively influence the burnout which was supported by the study of Ghalandari, et al. [23] which endorsed that surface acting strategy performed by emotional labor did not positively influence job burnout $(\mathrm{t}$-value $=1.449 ; \mathrm{sig}=0.150$ ) Regression findings predicted that in private hospitals, first model predicted that deep acting positively influenced the burnout while as in second model deep acting along with surface acting produced the same result. In the third model the surface acting, emotional consonance, deep acting produced the positive influence on burnout. Suppression had not contributed to the burnout as it was not included in the model as a significant predictor which is same as the study by Ian, et al. [24] which confirmed that expressing genuine positive emotions was associated with reduced emotional exhaustion, whereas contriving these emotions was a form of labour and increased emotional exhaustion. Suppressing negative emotions also constituted labour and contributed to emotional exhaustion. However, suppressing these emotions was not perceived as psychologically taxing by this sample and did not contribute significantly to emotional exhaustion [25].

\section{Recommendations}

From the findings of current study, it was found that emotional labour had a positive significant influence on burnout. In the fourth coming years, hospital sector is expected to get a boom and then a surge to compete is predicted in the tough competitive environment. To fight with the fatal diseases, employees have to increase their level of emotional labour as the other service sectors i.e. hospitality sector, air crews sector are doing for their survival. As rightly said, prevention is better than cure. Following are some recommendations to be followed to avoid burnout.

$>$ Since heavy work load has made employees helpless to spend time with their families so management should introduce recreational clubs, fun activities for employees and their families on every alternate weekend to give them a break from their monotonous and perceived boring schedules.

$>$ It has been observed that employees also feel physically exhausted. They feel tired, wiped out, sleepy and less energetic. To improve their physical fitness: their work load should be minimized. If it is not possible, then employees can choose a time during the day to shut out the outside world and indulge in some meditative music. Doing some deep breathing, visualizations and positive affirmations can help them to get rid of fatigue.

$>$ It is observed that employees in hospitals also feel mental exhaustion. So it is recommended that that they should be trained to do yoga and meditation. For this, workshops on yoga should be arranged.

$>$ From the findings, it has been found that employees sometimes feel depressed and anxious. They see themselves in trouble and feel trapped. The best way to reduce emotional exhaustion among employees is to provide them emotional support from their colleagues, management and from the relatives of the patients.

$>$ The hospital management should support the decisions of their employees in critical and difficult situations so that they feel emotionally supported. 


\section{Journal of Quality in Health Care \& Economics}

Employees should be sent to training programmers to develop necessary skills to adopt deep acting.

> Hospitals authorities should help their employees to deal with eccentric behavior of patients as difficult and threatening patients are also a source of burnout.

> Management should create cohesive environment where employees can openly discuss their frustrations caused by patients and their relatives.

\section{Limitations and Future Research}

The present study has a number of limitations that need to be addressed in future research. The sample consist of employed doctors, nurses and paramedical staff, so separate research can be conducted on nurses, doctors and paramedical staff to have a in depth insight into the variables and their effect. Future studies also need to examine the impact of emotional labour on employees' well-being and their performance. The researchers also need to explore the moderating effect of emotional intelligence on the relationship between emotional labour and emotional exhaustion. Emotional intelligence is the ability to understand own emotions and managing these emotions so its mediated role should be considered.

\section{References}

1. Hochschild AR (1983). The managed heart: Commercialization of human feeling. University of California Press, Berkeley, pp: 352.

2. Ashforth BE, Humphrey RH (1993) Emotional labor in service roles: The influence of identity. Academy of Management Review 18 (1): 88-115.

3. Morris JA, Feldman DC (1996) Managing emotions in the workplace. Journal of Managerial Issues 9(1): 257-274.

4. Grandey AA (2003) When "the show must go on": Surface acting and deep acting as determinants of emotional exhaustion and peer-rated service delivery. Academy of Management Journal 46 (1): 86-96.

5. Bernard J (1981) The Female World. McMillan Publishers, USA, pp: 614-614.

6. Hsieh C, Yang K (2004) Linking public service motivation with emotional labour in government: An Empirical Assessment.

7. Hennig T, Groth M, Panel M, Grember D (2006) Are all smiles created equal? How emotional contagion and emotional labor affect service relationships. Journal of Marketing 70(3): 58-73.

8. Maslach C, Schaufeli WB, Leiter MP (2001) Job Burnout. Annual Review of Psychology 52(3): 397422.

9. Wolfe GA (1981) Burnout of therapists: inevitable or preventable? Journal of the American Physical Therapy Association 61(7): 1046-1050.

10. Jonas WB (2005) Mosby's Dictionary of Complementary and Alternative Medicine. Elsevier Health Sciences Division, pp: 1-25.

11. Grandey AA, Cordeiro BL, Crouter AC (2005) A longitudinal and multi-source test of the work-family conflict and job satisfaction relationship. Journal of Occupational and Organizational Psychology 78(1): 120.

12. Warhurst C, Nickson D, Witz A, Cullen AM (2000) Aesthetic labour in interactive service work: some case study evidence from the 'new' Glasgow. The Service Industries Journal 20(3): 1-18.

13. Mohammedyfar MK, Khan MS, Tamini BK (2009) The effect of emotional intelligence and job burn out on mental and physical health. Journal of the Indian Academy of Applied Psychology 35(2): 219-226.

14. Noor NM, Zainuddin M (2011) Emotional labor and burnout among female teachers: Work-family conflict as mediator. Asian Journal of Social Psychology 14(4): 283-293.

15. Kim SY, Chang S., Kim HR (2002) A study on the relationship between emotional labor and depressive symptoms among Korean industrial service employees. Korean Journal of Occupational Environment Medicine 14 (3): 227-235.

16. Brotheridge CM, Grandy A (2001) Emotional Labor and Burnout: Comparing Two Perspectives of "People Work". Journal of Vocational Behavior 60(1): 17-39.

17. Celik M, Tabak A, Uysal MP, Signi U, Turunc O (2010) The Relationship between burnout and emotional labour of the employees in Hospital Sector. International Journal of Business and Management Studies 2 (1): 47-54.

18. Nearing G, Briet M, Brower A (2007) Validation of the Dutch Questionnaire on Emotional Labor (D-QEL) in 
Nurses and Teachers. Psychosocial resources in human services work, pp: 135-145.

19. Pines A, Aronson E (1988) Career burnout: Causes and cures. The Free Press, New York.

20. Ndetei DM, Pizzo M, Maru FA, Ongecha LI, Khasakhala $\mathrm{V}$, et al. (2008) Burnout in staff working at the Mathari psychiatric hospital. African Journal of Psychiatry 11(3): 199-203.

21. Kinman G, Wray S, Strange C (2011) Emotional labour, burnout and job satisfaction in UK teachers: the role of workplace social support, Educational Psychology. An International Journal of Experimental Educational Psychology 31 (7): 843-856.

22. Sutton RE (2005) Teachers' emotions and classroom effectiveness: Implications from recent research. The Clearing House 78(5): 229-234.
23. Ghalandari MK, Jogh, MGG (2012) The effect of emotional labor strategies (Surface acting and deep acting) on job satisfaction and job burnout in Iranian organizations: The Role of Emotional Intelligence. Interdisciplinary Journal of Research in Business 1(12): 24- 31.

24. Ian L, Durden G, Nick L, Cadogan J (2010) The role of emotional labour and role stress on burnout and psychological strain in high contact service employees. In: proceedings of Academy of Marketing Conference 2010, 6-9 July 2010, Coventry University, Coventry, UK.

25. Kent P, Judy FL (2007) Burnout in Nursing. Australian Journal of Advanced Nursing 24(3): 43-48. 